\title{
A Thermo-Hygro-Coupled Model for Chloride Penetration in Concrete Structures
}

\author{
Nattapong Damrongwiriyanupap, ${ }^{1}$ Suchart Limkatanyu, ${ }^{2}$ and Yunping $\mathrm{Xi}^{3}$ \\ ${ }^{1}$ Civil Engineering Program, School of Engineering, University of Phayao, Phayao 56000, Thailand \\ ${ }^{2}$ Department of Civil Engineering, Faculty of Engineering, Prince of Songkla University, Songkla 90112, Thailand \\ ${ }^{3}$ Department of Civil, Environmental, and Architectural Engineering, University of Colorado Boulder, Boulder, CO 80309, USA
}

Correspondence should be addressed to Nattapong Damrongwiriyanupap; nattapong.da@up.ac.th

Received 12 April 2015; Revised 26 June 2015; Accepted 29 June 2015

Academic Editor: Rui Wang

Copyright (c) 2015 Nattapong Damrongwiriyanupap et al. This is an open access article distributed under the Creative Commons Attribution License, which permits unrestricted use, distribution, and reproduction in any medium, provided the original work is properly cited.

\begin{abstract}
Corrosion damage due to chloride attack is one of the most concerning issues for long term durability of reinforced concrete structures. By developing the reliable mathematical model of chloride penetration into concrete structures, it can help structural engineers and management agencies with predicting the service life of reinforced concrete structures in order to effectively schedule the maintenance, repair, and rehabilitation program. This paper presents a theoretical and computational model for chloride diffusion in concrete structures. The governing equations are taking into account the coupled transport process of chloride ions, moisture, and temperature. This represents the actual condition of concrete structures which are always found in nonsaturated and nonisothermal conditions. The fully coupled effects among chloride, moisture, and heat diffusion are considered and included in the model. The coupling parameters evaluated based on the available material models and test data are proposed and explicitly incorporated in the governing equations. The numerical analysis of coupled transport equations is performed using the finite element method. The model is validated by comparing the numerical results against the available experimental data and a good agreement is observed.
\end{abstract}

\section{Introduction}

Corrosion of reinforcing steel is one of the main causes of deterioration process for reinforced concrete structures exposed to chloride-rich chemicals which are generally from deicing salts or sea water. The structures that are potentially threatened by the chloride attack are bridge decks, parking lots, and marine structures in splash and tidal zones. The corrosion of reinforcing steels eventually causes spalling, cracking, and delamination of concrete cover thus causing poor load bearing capacity and reducing aesthetic feature of the structures. The corrosion process can be divided into two periods, including an initiation period during which chloride ions penetrate into the concrete cover and initiate the corrosion of steel and a propagation period during which the rust deposits in the surrounding porous cement paste and results in cracking of concrete cover. The initiation period is usually much longer than the propagation period, because once the corrosion starts, it will take only a few years for the rust to crack the concrete cover. Therefore, improving the penetration resistance of concrete to various chloride sources is an important and challenging task in concrete and construction industries and equally important is to predict the chloride penetration process into concrete structures by theoretical and numerical models. The model prediction will provide useful information for structural engineers, owners, and management agencies to make correct decisions.

One of the theoretical models for predicting chloride ingress into concrete structures is based on Fick's second law, leading to a simple solution of one-dimensional linear ordinary partial differential diffusion equation [1-3]. The main problem of the simplified linear models is that the apparent diffusion coefficient in the model, $D_{a}$, has to be considered as a constant. In fact, it is not a constant and it varies by more than one order of magnitude and depends on many factors such as material characteristics and surrounding exposure 
conditions of structures. As a result, we cannot use the constant diffusion coefficient of concrete to reliably predict the service life of structures which have been exposed to a corrosive environment. Also, the apparent diffusion coefficient of concrete for a given location cannot be applied to use for other circumstances [4]. Furthermore, if the variations of initial and boundary conditions such as moisture and temperature surroundings were to be taken into account, the prediction error of using Fick's second law could be even larger. It was emphasized by Marchand and Samson [4] that Fick's model can only be appropriately used for concrete structures in saturated condition. However, the chloride exposure conditions of actual concrete structures are often found to be nonsaturated and nonisothermal. To solve this problem, some Fick's models have been modified to account for moisture and temperature effects [5-7]. This can be done either by using moisture and temperature dependent transport parameters or by incorporating the coupling terms in the chloride flux equation, which is adopted for the present study.

In saturated and isothermal conditions, chloride ions diffuse in concrete mainly due to its own concentration gradient. This means that there are no moisture and temperature effects on chloride penetration mechanism. On the contrary, the coupled diffusion process of chloride and moisture was evident in nonsaturated condition where the rate of chloride diffusion was accelerated by moisture gradient. Similarly, moisture flow was affected by the chloride transport mechanism $[8,9]$. For nonisothermal condition, chloride transport mechanism in concrete is driven by not only its concentration gradient but also temperature variation gradient. It was emphasized by Isteita [10] study that, by increasing temperature, the rate of chloride ingress into concrete can be increased.

Over the years, modeling of chloride transport in nonsaturated concrete has been studied by many researchers. Saetta et al. [6] proposed a numerical model of chloride penetration in partially saturated concrete. The model included the coupling effect of moisture movement on chloride diffusion. The transport equations of chloride and moisture were then solved using the finite element method. In 2000, Nilsson [11] developed a chloride diffusion model for the concrete exposed to seawater splash or deicing salts. It was found from the study that diffusion and convection mechanisms of chloride could be explained as a function of moisture content in concrete. Ababneh et al. [5] presented a mathematical model of chloride ingress into concrete in nonsaturated condition. The coupling term for the moisture movement was incorporated in the diffusing equation of chloride. The two coupled partial differential equations of chloride and moisture were analyzed using the finite difference method. The numerical results are validated against the available test data and the verification showed that the model could be used to simulate and predict chloride diffusion in nonsaturated concrete satisfactorily. Nielsen and Geiker [12] proposed a simplified Fick's model to examine chloride penetration into partially saturated concrete and studied the relationship between chloride diffusion coefficient and degree of saturation. Their findings showed that the chloride diffusion coefficient depends on degree of saturation of concrete. Conciatori et al. [13] presented a comprehensive model called "TransChlor" for simulating chloride diffusion associated with heat transfer, liquid and vapor movement, and carbon dioxide transport in concrete. Chloride profiles predicted by this model were validated with the experimental data and a good agreement was observed. Recently, Lin et al. [14] established a systematic and numerical model for predicting service life of concrete structures subjected to chloride attack. The effect of moisture transport on chloride diffusion was included in the chloride flux equation which was represented as the degree of water saturation. The numerical results obtained from the model showed that the service life of structures exposed to drying and wetting circumstances is significantly different from that under the saturated condition. Based on these studies, it can be concluded that moisture variation has a remarkable influence on degradation of concrete structures caused by chloride attack.

As noticed from the above review, most of the mathematical models have been focused on chloride diffusion in nonsaturated concrete, and the temperature effect on chloride transport has not been well investigated. The temperature variation is very significant and must be included in the mathematical model. A recent experimental study conducted by Isteita [10] showed that the rate of chloride penetration is accelerated by temperature gradients. The temperature variation has a significant effect on not only the chloride transport but also moisture movement. This can be described by Khoshbakht et al.'s [16] study where moisture diffusion in masonry walls is significantly influenced by heat transfer. However, there is no available mathematical model that takes into account the influences of temperature variation on simultaneous chloride and moisture diffusion in concrete. Therefore, in this study, a transport model based on Fick's law taking into account the fully coupled chloride, moisture, and heat flow in nonsaturated and nonisothermal concrete is developed. The coupling parameters related to chloride, moisture, and heat transport in concrete are characterized and explicitly incorporated in the governing equations. The governing equations are then solved numerically by the finite element method. The validation is performed by comparing the numerical results obtained from the present model with the available test data and a good agreement is observed.

\section{Basic Formulation of Governing Equations}

The flux of chloride ions through porous concrete depending on the concentration gradient is described by Fick's law as follows:

$$
J_{\mathrm{Cl}}=-D_{\mathrm{Cl}} \nabla C_{f}
$$

in which $J_{\mathrm{Cl}}$ is the flux of chloride ions, $D_{\mathrm{Cl}}$ is the diffusion coefficient of chloride ions, and $C_{f}$ is the free chloride concentration.

The total amount of moisture contained in concrete, the so-called moisture content, is generally represented by water content $(w)$ or by pore relative humidity $(H)$. In the present study, the moisture content in concrete is presented by pore 
relative humidity which consists of amount of liquid water and water vapor existing in concrete pores [17]. The moisture flux $\left(J_{H}\right)$ can be described in terms of the gradient of pore relative humidity given by

$$
J_{H}=-D_{H} \nabla H,
$$

where $D_{H}$ is the humidity diffusion coefficient. Heat flow in concrete is described by the well-known Fourier's law of heat conduction giving the heat flux in function of gradient of temperature:

$$
J_{\mathrm{Q}}=-D_{T} \nabla T,
$$

where $J_{\mathrm{Q}}$ is the heat flux, $D_{T}$ is the thermal diffusivity of concrete, and $T$ is temperature. As indicated earlier, in order to describe the coupled transport processes involving chloride, moisture, and temperature, the above listed three governing equations can be modified by adding new terms expressed explicitly in terms of the gradients of the state variables, and as a result, the three governing equations will become fully coupled and then these coupled equations must be solved simultaneously. For example, the flux of chloride ions $\left(J_{\mathrm{Cl}}\right),(1)$, in nonsaturated and nonisothermal concrete can be written as

$$
J_{\mathrm{Cl}}=-\left(D_{\mathrm{Cl}} \nabla C_{f}+D_{\mathrm{Cl}-H} \nabla H+D_{\mathrm{Cl}-T} \nabla T\right)
$$

in which $D_{\mathrm{Cl}-H}$ and $D_{\mathrm{Cl}-\mathrm{T}}$ are the coupling parameters corresponding to the effect of moisture and temperature variation on the chloride diffusion, respectively. Similar to chloride flux, the coupling terms are also included in moisture and heat flux. Then, (2) and (3) can be rewritten as

$$
\begin{gathered}
J_{H}=-\left(D_{H-C l} \nabla C_{f}+D_{H} \nabla H+D_{H-T} \nabla T\right), \\
J_{Q}=-\left(D_{T-C l} \nabla C_{f}+D_{T-H} \nabla H+D_{T} \nabla T\right),
\end{gathered}
$$

where $D_{H-C l}, D_{T-C l}, D_{H-T}$, and $D_{T-H}$ are coupling parameters. In general, coupling parameter $D_{i-j}$ represents the effect of $j$ process on the $i$ process.

The mass balance equations of chloride, moisture, and heat transport in concrete are given by (6), (7), and (8), respectively:

$$
\begin{aligned}
\frac{\partial C_{t}}{\partial t} & =\frac{\partial C_{t}}{\partial C_{f}} \frac{\partial C_{f}}{\partial t}=-\nabla J_{\mathrm{Cl}} \\
& =\nabla\left(D_{\mathrm{Cl}} \nabla C_{f}+D_{\mathrm{Cl}-H} \nabla H+D_{\mathrm{Cl}-T} \nabla T\right), \\
\frac{\partial w}{\partial t} & =\frac{\partial w}{\partial H} \frac{\partial H}{\partial t}=-\nabla J_{H} \\
& =\nabla\left(D_{H-C l} \nabla C_{f}+D_{H} \nabla H+D_{H-T} \nabla T\right), \\
\frac{\partial Q}{\partial t} & =\frac{\partial Q}{\partial T} \frac{\partial T}{\partial t}=-\nabla J_{\mathrm{Q}} \\
& =\nabla\left(D_{T-C l} \nabla C_{f}+D_{T-H} \nabla H+D_{T} \nabla T\right),
\end{aligned}
$$

in which $\partial C_{t} / \partial C_{f}, \partial w / \partial H$, and $\partial Q / \partial t$ represent the chloride binding capacity, moisture capacity, and heat capacity, respectively. The coupling parameters corresponding to the coupled transport mechanisms among chloride, moisture, and temperature will be explained later.

\section{Material Models}

To solve chloride, moisture, and heat transport in nonsaturated and nonisothermal concrete, the material parameters in the governing equations, (6), (7), and (8), need to be modeled first. This is because these material parameters are usually not constants but depend strongly on concrete mix design parameters, age of concrete, and concentrations of the transport variables, and therefore, material models must be developed to take into account the variations of influential parameters.

In the governing equations, the material parameters are chloride diffusion coefficient, chloride binding capacity; moisture diffusion coefficient, moisture capacity; thermal diffusivity, heat capacity, and coupling parameters. In this study, the influential parameters taken into account to characterize the coupled transport characteristics in concrete are concrete mix design parameters, that is, curing time, age of concrete, diffusivity of cement paste, and aggregate. One of the major improvements of the present mathematical model is that several material models based on available experimental data are proposed and incorporated in the governing equations. The determination of chloride diffusion coefficient, chloride binding capacity, moisture diffusion coefficient, and moisture binding capacity was once discussed in Damrongwiriyanupap et al. [18, 19]. For reader's convenience, we will summarily introduce the previously developed transport parameters and the coupling parameters will then be explained in detail.

3.1. Chloride Diffusion Coefficient $\left(D_{C l}\right)$. The diffusion coefficient of chloride ions in concrete can be evaluated using the multifactor equation given by

$$
D_{\mathrm{Cl}}=f_{1}\left(\frac{w}{c}, t_{0}\right) f_{2}\left(g_{i}\right) f_{3}(H) f_{4}(T) f_{5}\left(C_{f}\right)
$$

in which $f_{1}\left(w / c, t_{0}\right)$ represents a factor taking into account the influence of water cement ratio $(w / c)$ and curing time of concrete $\left(t_{0}\right)$. Porosity of concrete is directly affected by water cement ratio. The higher the water cement ratio, the higher the porosity and the higher the diffusion coefficient. A formulation for $f_{1}\left(w / c, t_{0}\right)$ was proposed by Xi and Bažant [20] and expressed as

$$
f_{1}=\frac{28-t_{0}}{62,500}+\left(\frac{1}{4}+\frac{\left(28-t_{0}\right)}{300}\right)\left(\frac{w}{c}\right)^{6.55} .
$$

The second factor is to consider concrete as a composite material comprising cement paste and aggregates. Thus, based on the composite action, the diffusivity of concrete can be evaluated simply by including the diffusivity of cement paste and aggregates. This factor can be calculated by using the threephase composite model developed by Christensen [21]:

$$
\begin{aligned}
& f_{2}\left(g_{i}\right) \\
& \quad=D_{\mathrm{cp}}\left(1+\frac{g_{i}}{\left(1-g_{i}\right) / 3+1 /\left(\left(D_{\mathrm{agg}} / D_{\mathrm{cp}}\right)-1\right)}\right),
\end{aligned}
$$

where $g_{i}$ is the volume fraction of aggregates in concrete and $D_{\text {agg }}$ and $D_{\text {cp }}$ are the diffusivity of aggregates and cement 
paste, respectively. These two parameters can be determined by using the model proposed by Martys et al. [22]:

$$
D=\frac{2\left(1-\left(V_{p}-V_{p}^{c}\right)\right)}{S^{2}}\left(V_{p}-V_{p}^{c}\right)^{4.2}
$$

in which $V_{p}$ is the porosity, $S$ denotes the surface area, and $V_{p}^{c}$ is the critical porosity (the porosity at which the pore space is first percolated). When (12) is used for the diffusivity of cement paste, $D_{c p}, V_{p}, S$, and $V_{p}^{c}$ are considered as the parameters for cement paste. The critical porosity may be taken as $3 \%$ for cement paste [22]. As previously proposed by Xi et al. [23], the surface areas of cement paste, $S$, can be defined by the monolayer capacity, $V_{m}$, of adsorption isotherm of concrete which is proportional to $S$. The porosity, $V_{p}$, can be estimated by adsorption isotherm, $n(H, T)=W_{\text {sol }} / W_{\text {conc }}$ at saturation $(H=1)$. $W_{\text {sol }}$ and $W_{\text {conc }}$ are the weight of pore solution and concrete, respectively. The explanation of adsorption isotherm of concrete can be found in $\mathrm{Xi}$ et al. $[23,24]$. It is mainly due to the fact that pores in aggregates are discontinuous. Thus, the diffusivity of aggregates, $D_{\text {agg }}$, can be considered as a very small value and simply taken as a constant with a proposed value in the literature $1 \times$ $10^{-12} \mathrm{~cm}^{2} / \mathrm{s}[5,20]$.

The third factor, $f_{3}(H)$, takes into account the dependence of chloride diffusion coefficient on the effect of internal relative humidity. A model developed by Bažant and Najjar [17] is used for this factor given by

$$
f_{3}(H)=\left(1+\frac{(1-H)^{4}}{\left(1-H_{C}\right)^{4}}\right)^{-1}
$$

in which $H_{c}$ is the critical humidity level at which the diffusion coefficient drops halfway between its maximum and minimum values $\left(H_{C}=0.75\right)$. When chloride ions transport in nonsaturated condition, (13) corresponds to the influence of coupling effect between the moisture and chloride diffusion.

To consider the effect of temperature on chloride diffusion in concrete, the fourth factor, $f_{4}(T)$, is included in the equation. This can be calculated by using Arrhenius' law:

$$
f_{4}(T)=\exp \left[\frac{U}{R}\left(\frac{1}{T_{0}}-\frac{1}{T}\right)\right]
$$

in which $U$ is the activation energy of the diffusion process, $R$ is the gas constant $\left(8.314 \mathrm{~J} \mathrm{~mol}^{-1} \mathrm{~K}^{-1}\right)$, and $T$ and $T_{0}$ are the current and reference temperatures, respectively, in Kelvin $\left(T_{0}=296 \mathrm{~K}\right)$. As reported by Collepardi et al. [25] and Page et al. [26], the activation energy of the diffusion process is a function of water cement ratio, $w / c$, and cement type which is illustrated in Table 1.

The fifth factor, $f_{5}\left(C_{f}\right)$, is to account for the dependence of the chloride diffusion coefficient on the free chloride concentration which can be expressed as

$$
f_{5}\left(C_{f}\right)=1-k_{\text {ion }}\left(C_{f}\right)^{m},
$$

where $k_{\text {ion }}$ and $m$ are two constants, 8.333 and 0.5 , respectively. $k_{\text {ion }}$ and $m$ were experimentally obtained by Xi and Bažant [20].
TABLE 1: Activation energies for various cement pastes.

\begin{tabular}{ccc}
\hline w/c & $\begin{array}{c}\text { Ordinary Portland cement } \\
(\mathrm{KJ} / \mathrm{mol})\end{array}$ & $\begin{array}{c}\text { Cement with pozzolans } \\
(\mathrm{KJ} / \mathrm{mol})\end{array}$ \\
\hline 0.4 & $41.8 \pm 4.0$ & - \\
0.5 & $41.8 \pm 4.0$ & 4.18 \\
0.6 & $41.8 \pm 4.0$ & - \\
\hline
\end{tabular}

3.2. Chloride Binding Capacity. Total chloride is generally defined as the summation of free chloride, $C_{f}$, and bound chloride, $C_{b}$. One can move independently through the interconnected pore networks called free chloride. The others can be chemically and physically bound to the pore wall represented as bound chloride. Only free chloride can initiate the corrosion of rebar. The total chloride concentration is given by

$$
C_{t}=C_{f}+C_{b}
$$

Bound chloride can be explained in terms of chloride binding capacity expressed as

$$
\frac{d C_{f}}{d C_{t}}=\frac{1}{1+d C_{b} / d C_{f}} .
$$

The model of chloride binding capacity based on Freundlich isotherm proposed by Xi and Bažant [20] is adopted for this study and is written as

$$
\begin{aligned}
& \frac{d C_{f}}{d C_{t}} \\
& =\frac{1}{1+\left(A 10^{B} \beta_{C-S-H} / 35,450 \beta_{\text {sol }}\right)\left(C_{f} / 35.45 \beta_{\text {sol }}\right)^{A-1}},
\end{aligned}
$$

where two constants, $A$ and $B$, are experimentally obtained from chloride adsorption which are equal to 0.3788 and 1.14 , respectively. More details on another two parameters, $\beta_{\text {sol }}$ and $\beta_{C-S-H}$, can be found in $\mathrm{Xi}$ and Bažant [20]. The use of chloride binding capacity illustrated in (18) is restricted when free chloride content, $C_{f}$, equals zero because of $A<1$. This condition gives $\partial C_{f} / \partial C_{t}=0$ resulting in $\partial C_{f} / \partial t=0$ which means $C_{f}$ is consistent and equivalent to initial free chloride concentration. Thus, chloride diffusion will no longer initiate. To solve this problem, the Freundlich isotherm is used when $C_{f}$ is large $(>0.01 \mathrm{~mol} / \mathrm{L})$ and the Langmuir isotherm is applied when $C_{f}$ is small $(<0.05 \mathrm{~mol} / \mathrm{L})$ suggested by Tang and Nilsson [27]. The chloride binding capacity based on the Langmuir isotherm is given by

$$
\frac{d C_{f}}{d C_{t}}=\frac{1}{1+d C_{b} / d C_{f}}=\frac{1}{1+1 / \alpha\left(\beta C_{f}+1 / \alpha\right)^{2}}
$$

in which

$$
\begin{aligned}
& \alpha=\frac{k^{\prime} C_{b m} \beta_{C-S-H}}{35,450 \beta_{\text {sol }}}, \\
& \beta=\frac{1,000}{\beta_{C-S-H} C_{b m}} .
\end{aligned}
$$


The parameters involved in (20) are proposed by Tang and Nilsson [27]; that is, $1 / C_{b m}=0.1849,1 /\left(k^{\prime} C_{b m}\right)=0.002438$, $k^{\prime}=75.841$, and $C_{b m}=5.4083$.

3.3. Moisture Diffusion Coefficient. The moisture diffusion coefficient of concrete can be characterized using the theoretical formulation of composite-based materials derived by Christensen [21] and expressed as

$$
\begin{aligned}
& D_{H} \\
& =D_{H_{\mathrm{cp}}}\left(1+\frac{g_{i}}{\left(1-g_{i}\right) / 3+1 /\left[\left(D_{H_{\mathrm{agg}}} / D_{H_{\mathrm{cp}}}\right)-1\right]}\right)
\end{aligned}
$$

in which $g_{i}$ is the volume fraction of aggregates, $D_{H_{\mathrm{cp}}}$ is the moisture diffusivity of the cement paste, and $D_{H_{\text {agg }}}$ is the moisture diffusivity of the aggregates. It is due to the fact that the rate of moisture diffusion through discontinuous pores that appeared in aggregates is much slower than that in cement paste. Therefore, $D_{H_{\text {agg }}}$ in (21) can be neglected. The moisture diffusivity of cement paste can be evaluated by the empirical model proposed by Xi et al. [24].

3.4. Moisture Capacity. The moisture capacity of concrete can be simply calculated by taking the proportion of the moisture capacities of cement paste and aggregate as proposed by $\mathrm{Xi}$ et al. [28]:

$$
\frac{d w}{d H}=f_{\mathrm{agg}}\left(\frac{d w}{d H}\right)_{\mathrm{agg}}+f_{\mathrm{cp}}\left(\frac{d w}{d H}\right)_{\mathrm{cp}}
$$

where $f_{\text {agg }}$ and $f_{\mathrm{cp}}$ are the weight percentages of the aggregate and cement paste, respectively; $(d w / d H)_{\text {agg }}$ and $(d w / d H)_{\mathrm{cp}}$ are the moisture capacity of aggregate and cement paste, respectively. The parameters given in (22) can be determined based on the model developed by $\mathrm{Xi}$ et al. [23, 24] and $\mathrm{Xi}$ $[29,30]$.

3.5. Coupling Parameters. In this study, the fully coupled transport equations of chloride, moisture, and heat are formulated based on modified Fick's law. The coupling terms are explicitly incorporated in the governing equations as illustrated in (6), (7), and (8). There are mainly six coupling parameters: (1) the effect of moisture on chloride transport $\left(D_{\mathrm{Cl}-\mathrm{H}}\right)$, (2) the effect of chloride on moisture transport $\left(D_{H-C l}\right)$, (3) the influence of heat conduction on chloride transport $\left(D_{\mathrm{Cl}-\mathrm{T}}\right),(4)$ the influence of heat conduction on moisture transport $\left(D_{H-T}\right),(5)$ the effect of chloride transport on heat conduction $\left(D_{T-C l}\right)$, and (6) the influence of moisture transport on heat conduction $\left(D_{T-H}\right)$. The detail of these parameters will be explained as follows.

3.5.1. $D_{\mathrm{Cl}-\mathrm{H}}$ and $\mathrm{D}_{\mathrm{H}-\mathrm{Cl}}$. There have been several investigations in the literature, as previously reviewed, on the effect of moisture on chloride diffusion in concrete and the results have shown that chloride ingress in concrete is strongly affected by moisture variation. This has been particularly confirmed by the experimental studies conducted by Abarr [9] and Nagesh and Bhattacharjee [31] where chloride penetration into concrete depends on degree of saturation and moisture gradient. In particular, the rate of chloride transport can be accelerated by a moisture gradient when the two gradients are in the same direction. On the other hand, the chloride flux can be reduced by a moisture gradient when the two gradients are not in the same direction. Another finding from these two studies was that the apparent chloride diffusion coefficient obtained under unsaturated condition was chloride concentration dependent.

Similarly, it has been found from the experiment conducted by Ababneh and $\mathrm{Xi}$ [8] that the moisture transport in concrete is influenced by chloride transport. Their results indicated that the coupling parameter due to the effect of chloride transport on moisture penetration in concrete is concentration dependent, depending on the concentration of chloride.

Because both $D_{\mathrm{Cl}-\mathrm{H}}$ and $D_{\mathrm{H}-\mathrm{Cl}}$ are chloride concentration dependent, we can use the following simplified models to describe them:

$$
\begin{aligned}
& D_{\mathrm{Cl}-\mathrm{H}}=\varepsilon \mathrm{Cl}_{f}, \\
& D_{H-\mathrm{Cl}}=\delta \mathrm{Cl}_{f},
\end{aligned}
$$

in which $\varepsilon$ and $\delta$ are two material constants depending on concrete mix design and age of concrete. In order to determine $\varepsilon$ and $\delta$, the chloride profiles obtained from the numerical results of coupled chloride and moisture diffusion in concrete are plotted against the test data by Abarr [9]. For a specific concrete at a certain age, the two constants can be estimated by the best curve fitting between test data and numerical results of coupled chloride and moisture transport in concrete. The two material constants were analyzed based on available test data and determined in a previous study, $\varepsilon=$ 0.19 and $\delta=0.52[19]$.

3.5.2. $\mathrm{D}_{\mathrm{Cl}-\mathrm{T}}$. The available material model on this parameter developed by Isteita [10] is used in the present mathematical model. The study was carried out under chloride ponding test with various temperature conditions. The concrete specimens were ponded with $3 \% \mathrm{NaCl}$ solution on the top surface. The results revealed that when the temperature of the chloride solution is increased, chloride ions penetrate faster from the top to bottom of concrete samples. This means the increasing temperature gradient contributes significantly to chloride penetration. So, under nonisothermal condition, the coupling effect due to the effect of temperature variation on chloride penetration cannot be simply ignored. A model for this coupling parameter was developed by Isteita [10] using a multifactor equation taking into account the influential parameters such as free chloride concentration, age of concrete, and temperature given by

$$
D_{\mathrm{Cl}-T}=5 \times 10^{-8} C_{f} f_{1}(t) f_{2}(T),
$$

where $f_{1}(t)$ is the factor considering the age effect of concrete which corresponds to the degree of hydration of concrete:

$$
f_{1}(t)=4 t^{-1}
$$


in which $t$ represents the age of concrete. The temperature effect is taken into account and given by the second factor, $f_{2}(T)$. Using Arrhenius's equation, it is written as

$$
f_{2}(T)=\exp \left(0.1 \frac{U}{R}\left(\frac{1}{T_{\text {ref }}}-\frac{1}{T}\right)\right),
$$

where $U$ is the activation energy of the diffusion process; $R$ is the universal gas constant; $T$ and $T_{\text {ref }}$ are current and reference temperatures, respectively. It is important to point out that the value $5 \times 10^{-8}$ in (24) is only valid for the concrete used in the study by Isteita [10], and the value will vary when a concrete with a different mix design is to be used.

3.5.3. $D_{H-T}$. It should be pointed out that the available test data and/or material models regarding the influence of temperature on moisture diffusion in concrete are still very limited. So far, most research has focused on the influence of temperature change on moisture transport in high temperature range but very few publications have considered the moisture-temperature coupling effect in normal temperature. An investigation on the influence of temperature variation on moisture movement for concrete was carried out by Khoshbakht et al. [16] and a model for the coupling parameter was developed as shown in (27). Due to data scarcity, we used this model as a simple approximation for the coupled effect of temperature variation on moisture diffusion in concrete in the present study:

$$
\begin{aligned}
& D_{H-T}=\rho_{0}\left(1.67 \times 10^{-8} \theta^{5}-3.99 \times 10^{-6} \theta^{4}+2.58\right. \\
& \left.\quad \times 10^{-4} \theta^{3}-4.14 \times 10^{-3} \theta^{2}+0.216 \theta-0.035\right) \\
& \quad \times 10^{-3}, \\
& \theta=226.68 H^{3}-247.75 H^{2}+123.45 H+0.1076,
\end{aligned}
$$

in which $\rho_{0}=2,200 \mathrm{~kg} / \mathrm{m}^{3}, \theta$ is the moisture content, and $H$ is relative humidity.

3.5.4. $D_{T-H}$ and $D_{T-C l}$. Theoretically, both chloride and moisture transport in concrete have some effects on temperature variation because the mass transports carry heat with them. However, the level of chloride concentration is low and the intensity of moisture transport is small (no liquid flow in good quality concrete), and these two coupling effects can be dropped [16]. So, the parameters $D_{T-H}$ and $D_{T-C l}$ are not included in the governing equations.

\section{Numerical Results and Discussions}

A concrete specimen with $3 \mathrm{~cm}$ by $5 \mathrm{~cm}$, as shown in Figure 1, is numerically analyzed using the finite element method. The sample is exposed to $1 \mathrm{~mol} / \mathrm{L} \mathrm{NaCl}$ solution and, at the top surface, the relative humidity and temperature are initially specified as $100 \% \mathrm{RH}$ and $35^{\circ} \mathrm{C}$, respectively. The inside relative humidity and temperature are given as $50 \%$ $\mathrm{RH}$ and $20^{\circ} \mathrm{C}$, respectively. The other boundaries are assumed to be sealed without any exchange of moisture, chloride, and

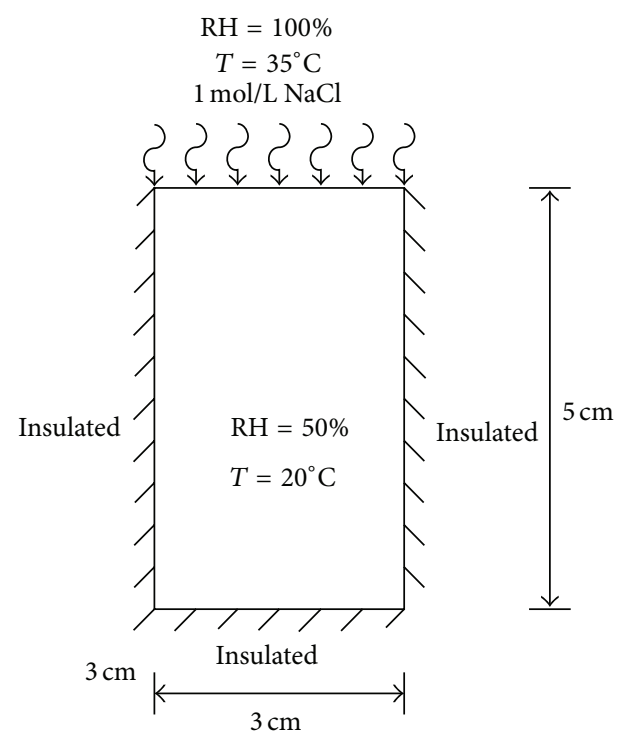

FIGURE 1: Concrete sample used in the numerical simulation.

TABLE 2: Material parameters and input data for simulated concrete specimen.

\begin{tabular}{lc}
\hline Parameter & Value \\
\hline Water to cement ratio, w/c & 0.55 \\
Volume fraction of aggregate, $g_{i}$ & 0.65 \\
Cement type & $\mathrm{I}$ \\
Curing time (days) & 28 \\
Heat capacity, $\partial Q / \partial T$ & ${ }^{*} 1,000$ \\
$\left(\mathrm{~J} / \mathrm{kg}^{\circ} \mathrm{K}\right)$ & \\
${\text { Thermal diffusivity, } D_{T}}_{\left(\mathrm{W} / \mathrm{m}^{\circ} \mathrm{K}\right)}$ & ${ }^{*} 2$ \\
\hline
\end{tabular}

${ }^{*}$ The values are taken from Isgor and Razaqpur [15].

heat. The defined material parameters and input data for the numerical analysis related to the governing equations are shown in Table 2.

Figures 2, 3, and 4 demonstrate moisture profiles of concrete samples at 10,50, and 100 days of exposure, respectively. As seen from these figures, at any fixed depth, pore relative humidity of nonsaturated concrete is lower than the saturated condition. When the temperature effect is considered, the moisture level at any fixed depth is higher than that without the temperature effect because the moisture transport is accelerated by the temperature gradient. This effect is less significant at 100 days of exposure because the concrete becomes saturated. Figure 5 shows the distribution profiles of free chloride concentration at different times of exposure at nonsaturated and nonisothermal conditions. The initial chloride concentration inside concrete sample is assumed to be zero so that chloride ions penetrate from outside (top surface) to inside specimen. This can be noticed from Figure 5 where the free chloride concentration decreases with increasing depth from the top surface. The trends also illustrate that, at any depth, the free chloride concentration is higher when exposure time is longer. 

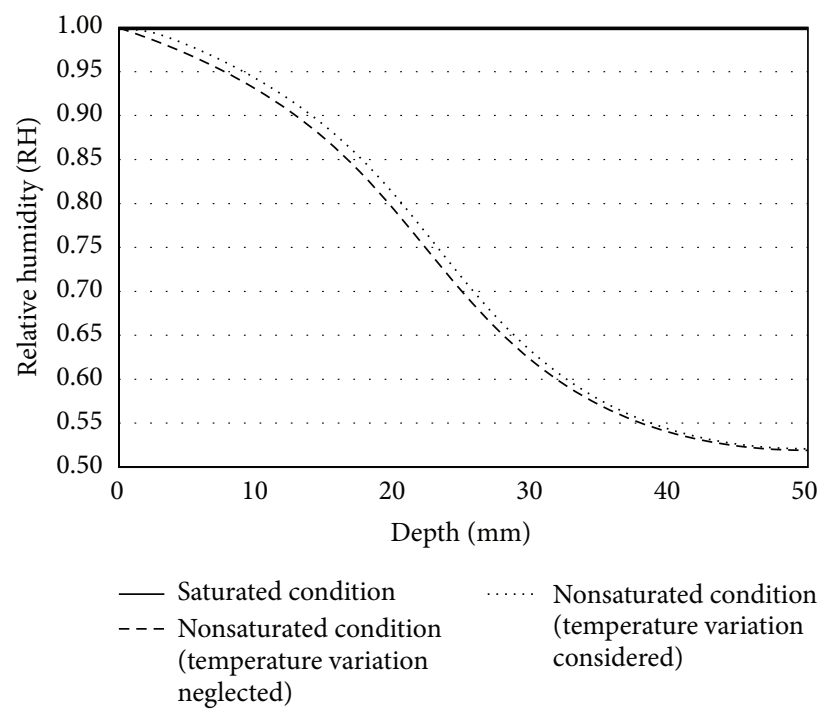

Nonsaturated condition (temperature variation considered)

FIGURE 2: Moisture profiles at 10 days of exposure.

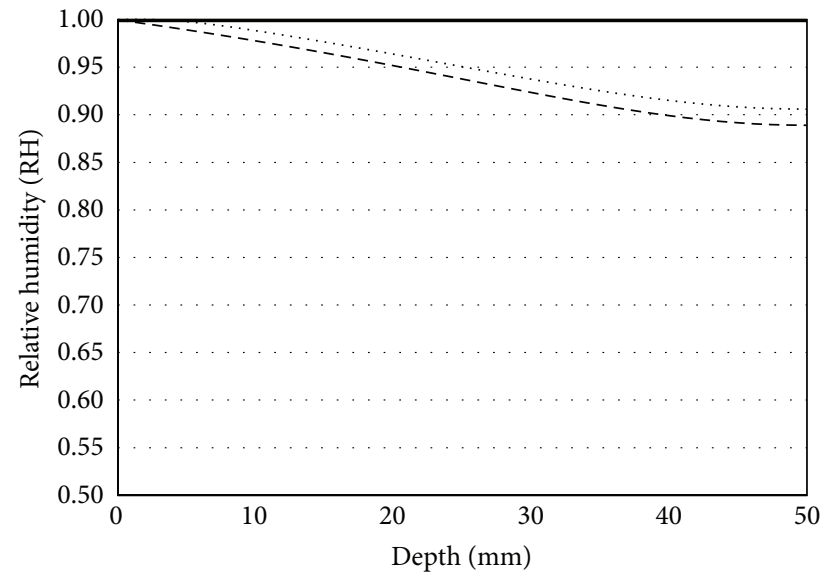

- Saturated condition

- - - Nonsaturated condition (temperature variation neglected)

Nonsaturated condition (temperature variation considered)

FIGURE 3: Moisture profiles at 50 days of exposure.

Free chloride concentration is plotted against the depth from the top surface at 10,50, and 100 days of exposure as shown in Figures 6, 7, and 8, respectively. As observed from these figures, at any fixed depth, the chloride concentration at nonsaturated condition is higher than saturated state. This is because, as explained earlier, the chloride penetration is accelerated by the moisture penetration when they are in the same direction. Figures 6,7 , and 8 also show that when the temperature variation is taken into account, the change of chloride concentration can be apparently observed. Heat flow can accelerate the diffusion rate of both moisture and chloride. As mentioned previously, moisture diffusion can carry chloride ions so that, with increasing rate of moisture transport due to the temperature effect, chloride ions can ingress faster

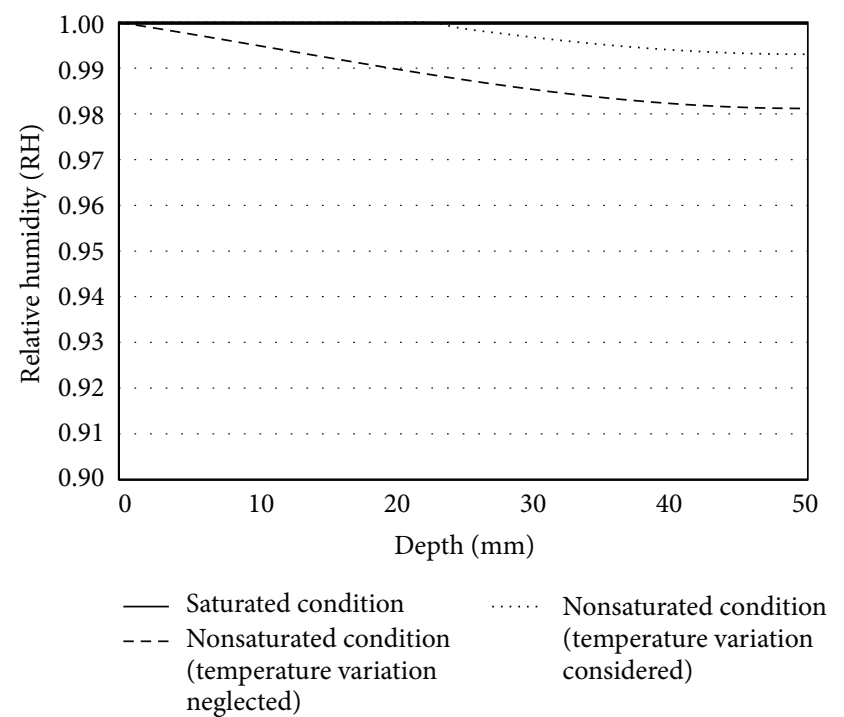

FIGURE 4: Moisture profiles at 100 days of exposure.

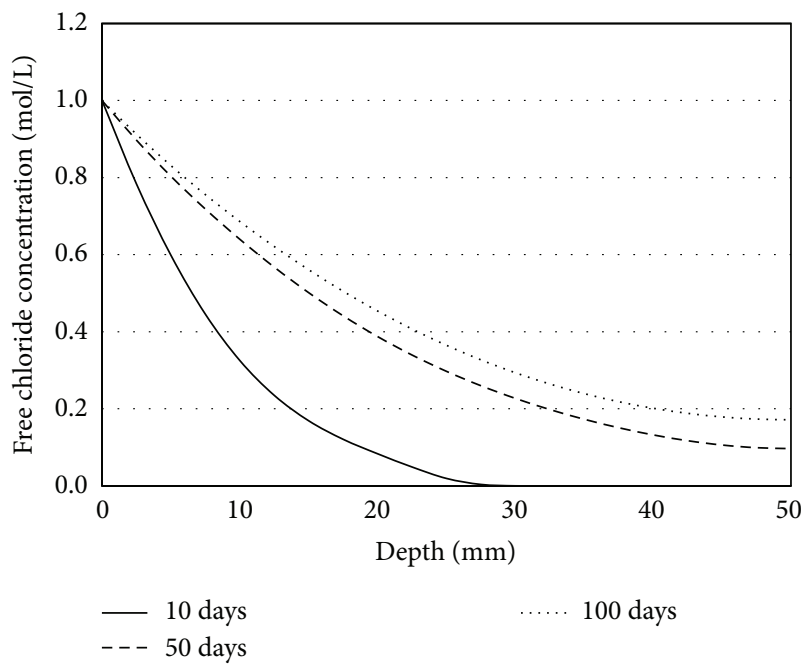

FIGURE 5: Free chloride concentration profiles at different times of exposure.

leading to higher concentration. Thus, from chloride concentration profiles as shown in Figures 6 through 8, it can be concluded that the coupled effects of temperature variation and moisture transport on chloride diffusion in concrete are very significant and they cannot be negligible. The present model takes into account the coupling parameters very well and the model can be used to simulate chloride transport in concrete structures which is frequently found in nonsaturated and nonisothermal condition.

\section{Model Validation}

Due to the lack of systematic test data in the literature on chloride diffusion in nonsaturated and nonisothermal condition, 


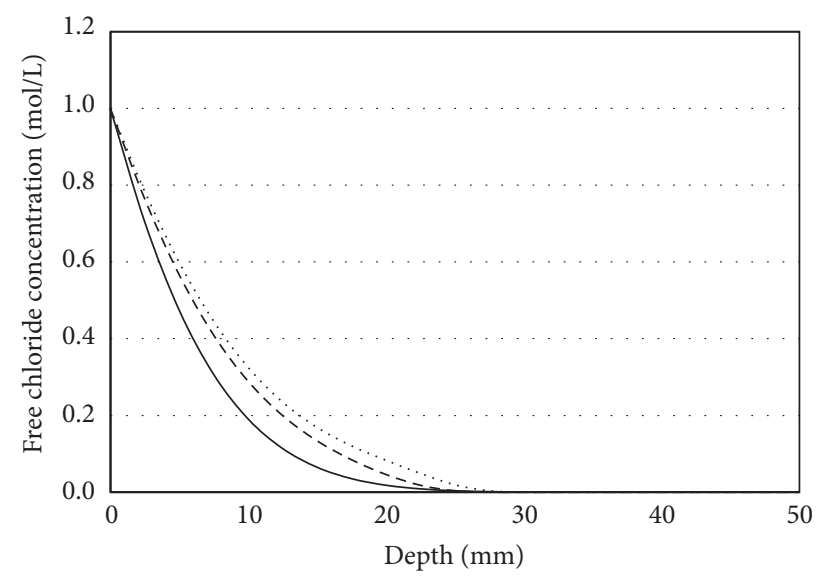

$\begin{array}{lll}\text { - Saturated condition } & \cdots \cdots & \begin{array}{l}\text { Nonsaturated condition } \\ \text { (temperature variation } \\ \text { considered) }\end{array} \\ & \begin{array}{l}\text { Nonsaturated condition } \\ \text { (temperature variation } \\ \text { neglected) }\end{array}\end{array}$

FIGURE 6: Free chloride concentration profiles at 10 days of exposure.
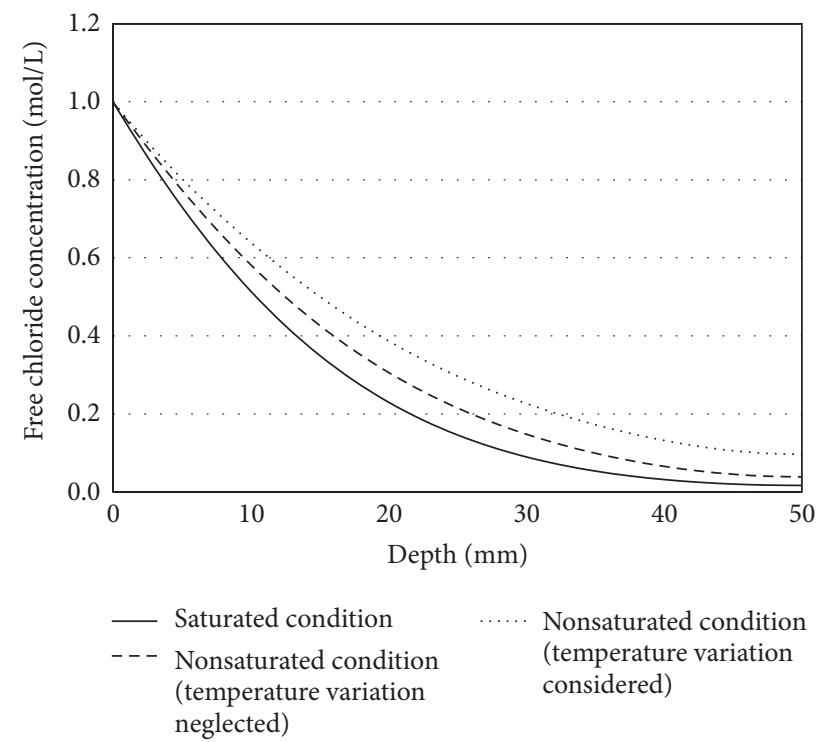

Nonsaturated condition (temperature variation considered)

FIGURE 7: Free chloride concentration profiles at 50 days of exposure.

we compare the present numerical results to available experimental data which were conducted using chloride ponding test in (1) nonsaturated and isothermal condition and (2) saturated and nonisothermal condition.

Figure 9 shows the comparison between numerical results obtained from the present model and the test data conducted on chloride ponding test at 90 days of exposure by Andrade and Whiting [32]. The experiment was performed on concrete with two different water cement ratios, $w / c=0.4$ and 0.6. The concrete samples were kept in nonsaturated and isothermal condition. As illustrated from Figure 9, a good agreement is observed. Figures 10 and 11 demonstrate the verification of the proposed model with test results of chloride ponding test on concrete in nonisothermal and saturated

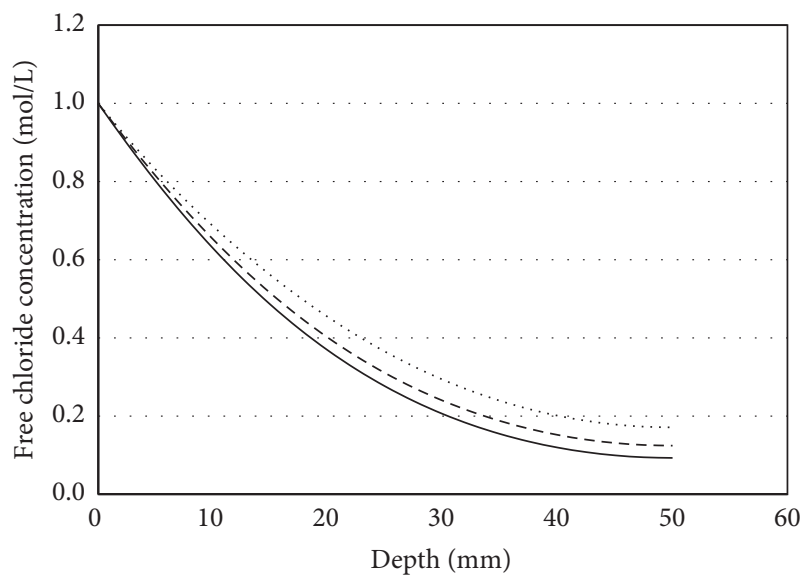

$\begin{array}{lrl}\text { Saturated condition } & \cdots \cdots & \begin{array}{l}\text { Nonsaturated condition } \\ \text { (temperature variation }\end{array} \\ \text { considered) }\end{array}$

FIgURE 8: Free chloride concentration profiles at 100 days of exposure.

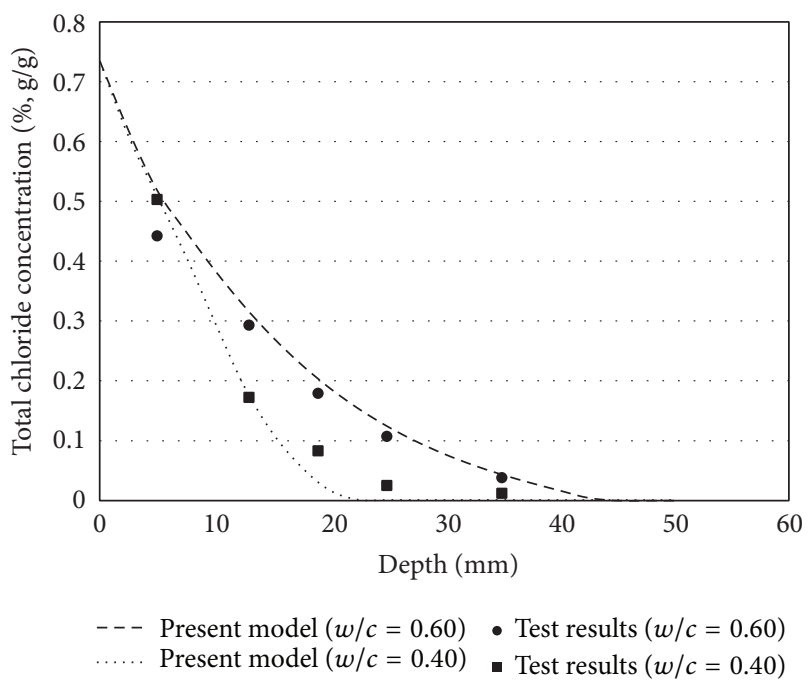

FIGURE 9: A comparison between numerical results and experimental data.

condition. The concrete sample was exposed to $3 \% \mathrm{NaCl}$ solution at the top surface. The experiments were carried out at 6 and 12 days of exposure with the controlled temperature at the exposed (top) surface, $T=35^{\circ} \mathrm{C}$. The temperature inside specimens was maintained at $T=20^{\circ} \mathrm{C}$. It can be seen from Figures 10 and 11 that the present model is satisfactory to predict chloride ingress into nonisothermal and saturated concrete. Based on the present comparative studies, it may be concluded that the present mathematical model can be used to adequately predict chloride penetration in nonsaturated and isothermal and nonisothermal and saturated concrete structures. 


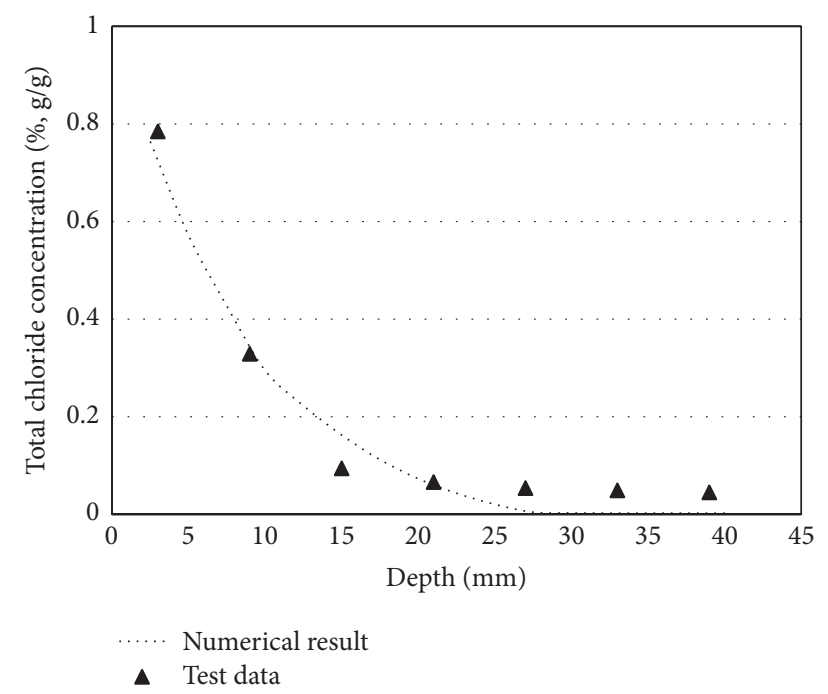

Figure 10: A comparison between numerical result and test data at 6 days of a specimen exposed to $T=35^{\circ} \mathrm{C}$.

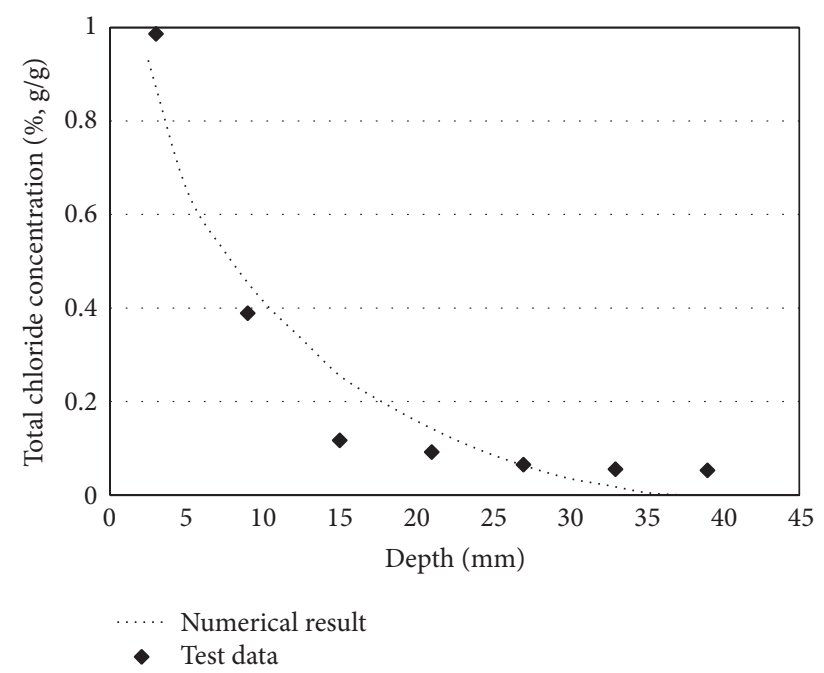

FIGURE 11: A comparison between numerical result and test data at 12 days of a specimen exposed to $T=35^{\circ} \mathrm{C}$.

\section{Conclusions}

(1) A mathematical model for predicting chloride ingress into concrete is developed based on Fick's law. The model takes into account the fully coupled effect among chloride, moisture, and heat transport. The governing equations are established by including additional terms in the flux equations. The additional terms are explicitly related to the concentration gradients of the state variables, that is, free chloride concentration, pore relative humidity, and temperature.

(2) The material models developed for the transport parameters of chloride and moisture diffusion in concrete are introduced. These parameters include chloride diffusion coefficient, chloride binding capacity, moisture diffusivity, and moisture capacity. Some of these parameters are taking into account the factors affecting concrete mix design such as water cement ratio, curing time, and type of cement.
(3) The proposed coupling parameters between chloride and moisture transport are characterized based on available experimental data. These parameters are not constant but expressed in terms of chloride content dependent. And the material parameters which accounted for the influence of temperature variation on chloride and moisture diffusion are obtained from available material models.

(4) Finite element numerical simulation model is developed and the model demonstrates that temperature variation has a remarkable influence on moisture and chloride distribution profiles. In nonsaturated concrete, chloride penetration is accelerated by moisture movement when the two gradients are in the same direction.

(5) For nonsaturated concrete under nonisothermal condition, chloride flux profiles at any exposure times are significantly influenced by variations in moisture diffusion and heat transfer. These examples exhibit the strong-coupling effect of not only moisture but also heat transfer on chloride transport mechanism. The chloride penetration is accelerated by the heat flow when the two gradients are in the same direction.

(6) Compared to other models which use Fick's second law and combine all coupling effects into one parameter, that is, the apparent chloride diffusivity, the present model has explicit and distinct term in each of the governing equations to reflect the effect of each coupling process. Therefore, the present model is a significant improvement in the aspect of modifying the governing equations of chloride, moisture, and heat by incorporating the coupling parameters.

(7) The present model is validated by comparing the numerical results with the available chloride ponding test data obtained in two separated tests. One is under nonsaturated and isothermal condition, and the other is under nonisothermal but saturated condition. Good agreement is satisfactorily obtained.

(8) There is a lack of experimental data for chloride penetration into concrete under fully coupled nonsaturated and nonisothermal condition. Future work is needed to further improve this model by verifying the numerical results with the experimental data with the fully coupled condition.

\section{Conflict of Interests}

The authors declare that there is no conflict of interests regarding the publication of this paper.

\section{Acknowledgments}

The financial supports from the Thailand Research Fund (TRF) under Grant MRG5580222 and under NSF Grant CMMI-0727749 to the University of Colorado Boulder and the University of New Hampshire are gratefully acknowledged.

\section{References}

[1] R. J. Detwiler, D. A. Whiting, and E. S. Lagergren, "Statistical approach to ingress of chloride ions in silica fume concrete for bridge decks," ACI Materials Journal, vol. 96, no. 6, pp. 670-675, 1999. 
[2] A. K. Tamimi, J. A. Abdalla, and Z. I. Sakka, "Prediction of long term chloride diffusion of concrete in harsh environment," Construction and Building Materials, vol. 22, no. 5, pp. 829-836, 2008.

[3] K. A. T. Vu and M. G. Stewart, "Structural reliability of concrete bridges including improved chloride-induced corrosion models," Structural Safety, vol. 22, no. 4, pp. 313-333, 2000.

[4] J. Marchand and E. Samson, "Predicting the service-life of concrete structures-limitations of simplified models," Cement and Concrete Composites, vol. 31, no. 8, pp. 515-521, 2009.

[5] A. Ababneh, F. Benboudjema, and Y. Xi, "Chloride penetration in nonsaturated concrete," Journal of Materials in Civil Engineering, vol. 15, no. 2, pp. 183-191, 2003.

[6] A. V. Saetta, R. V. Scotta, and R. V. Vitaliani, "Analysis of chloride diffusion into partially saturated concrete," ACI Materials Journal, vol. 90, no. 5, pp. 441-451, 1993.

[7] Suwito, X. C. Cai, and Y. Xi, "Parallel finite element method for coupled chloride moisture diffusion in concrete," International Journal of Numerical Analysis and Modeling, vol. 3, no. 4, pp. 481-503, 2006.

[8] A. Ababneh and Y. Xi, "An experimental study on the effect of chloride penetration on moisture diffusion in concrete," Materials and Structures, vol. 35, no. 254, pp. 659-664, 2002.

[9] L. Abarr, The effect of moisture diffusion on chloride penetration [M.S. thesis], University of Colorado, Boulder, Colo, USA, 2005.

[10] M. Isteita, The effect of thermal conduction on chloride penetration in concrete [M.S. thesis], University of Colorado, Boulder, Colo, USA, 2009.

[11] L. O. Nilsson, "A numerical model for combined diffusion and convection of chloride in non-saturated concrete," in Second International RILEM Workshop on Testing and Modelling the Chloride Ingress into Concrete, pp. 261-275, RILEM, 2000.

[12] E. P. Nielsen and M. R. Geiker, "Chloride diffusion in partially saturated cementitious material," Cement and Concrete Research, vol. 33, no. 1, pp. 133-138, 2003.

[13] D. Conciatori, F. Laferrière, and E. Brühwiler, "Comprehensive modeling of chloride ion and water ingress into concrete considering thermal and carbonation state for real climate," Cement and Concrete Research, vol. 40, no. 1, pp. 109-118, 2010.

[14] G. Lin, Y. Liu, and Z. Xiang, "Numerical modeling for predicting service life of reinforced concrete structures exposed to chloride environments," Cement and Concrete Composites, vol. 32, no. 8, pp. 571-579, 2010.

[15] O. B. Isgor and A. G. Razaqpur, "Finite element modeling of coupled heat transfer, moisture transport and carbonation processes in concrete structures," Cement and Concrete Composites, vol. 26, no. 1, pp. 57-73, 2004.

[16] M. Khoshbakht, M. W. Lin, and C. A. Feickert, "A finite element model for hygrothermal analysis of masonry walls with FRP reinforcement," Finite Elements in Analysis and Design, vol. 45, no. 8-9, pp. 511-518, 2009.

[17] Z. P. Bažant and L. J. Najjar, "Nonlinear water diffusion in nonsaturated concrete," Matériaux et Constructions, vol. 5, no. 1, pp. 3-20, 1972.

[18] N. Damrongwiriyanupap, L. Li, and Y. Xi, "Coupled diffusion of chloride and other ions in saturated concrete," Frontiers of Architecture and Civil Engineering in China, vol. 5, no. 3, pp. 267-277, 2011.

[19] N. Damrongwiriyanupap, L. Li, and Y. Xi, "Coupled diffusion of multi-component chemicals in non-saturated concrete," Computers and Concrete, vol. 11, no. 3, pp. 201-222, 2013.
[20] Y. Xi and Z. P. Bažant, "Modeling chloride penetration in saturated concrete," Journal of Materials in Civil Engineering, vol. 11, no. 1, pp. 58-65, 1999.

[21] R. M. Christensen, Mechanics of Composite Materials, Wiley Interscience, New York, NY, USA, 1979.

[22] N. S. Martys, S. Torquato, and D. P. Bentz, "Universal scaling of fluid permeability for sphere packings," Physical Review E, vol. 50, no. 1, pp. 403-408, 1994.

[23] Y. Xi, Z. P. Bažant, and H. M. Jennings, "Moisture diffusion in cementitious materials adsorption isotherms," Advanced Cement Based Materials, vol. 1, no. 6, pp. 248-257, 1994.

[24] Y. Xi, Z. P. Bažant, L. Molina, and H. M. Jennings, "Moisture diffusion in cementitious materials: moisture capacity and diffusivity", Journal of Advanced Cement-Based Materials, vol. 1, no. 6, pp. 258-266, 1994.

[25] M. Collepardi, A. Marcialis, and R. Turriziani, "Penetration of chloride ions into cement pastes and concretes," Journal of the American Ceramic Society, vol. 55, no. 10, pp. 534-535, 1972.

[26] C. L. Page, N. R. Short, and A. El Tarras, "Diffusion of chloride ions in hardened cement pastes," Cement and Concrete Research, vol. 11, no. 3, pp. 395-406, 1981.

[27] L. Tang and L. O. Nilsson, "Chloride binding capacity and binding isotherms of OPC pastes and mortars," Cement and Concrete Research, vol. 23, no. 2, pp. 247-253, 1993.

[28] Y. Xi, K. Willam, and D. M. Frangopol, "Multiscale modeling of interactive diffusion processes in concrete," Journal of Engineering Mechanics, vol. 126, no. 3, pp. 258-265, 2000.

[29] Y. Xi, "A model for moisture capacities of composite materials Part I: formulation," Computational Materials Science, vol. 4, no. 1, pp. 65-77, 1995.

[30] Y. Xi, "A model for moisture capacities of composite materials Part II: application to concrete," Computational Materials Science, vol. 4, no. 1, pp. 78-92, 1995.

[31] M. Nagesh and B. Bhattacharjee, "Modeling of chloride diffusion in concrete and determination of diffusion coefficients," ACI Materials Journal, vol. 95, no. 2, pp. 113-120, 1998.

[32] C. Andrade and D. Whiting, "A comparison of chloride ion diffusion coefficients derived from concentration gradients and non-steady state accelerated ionic migration," Materials and Structures, vol. 29, no. 8, pp. 476-484, 1996. 

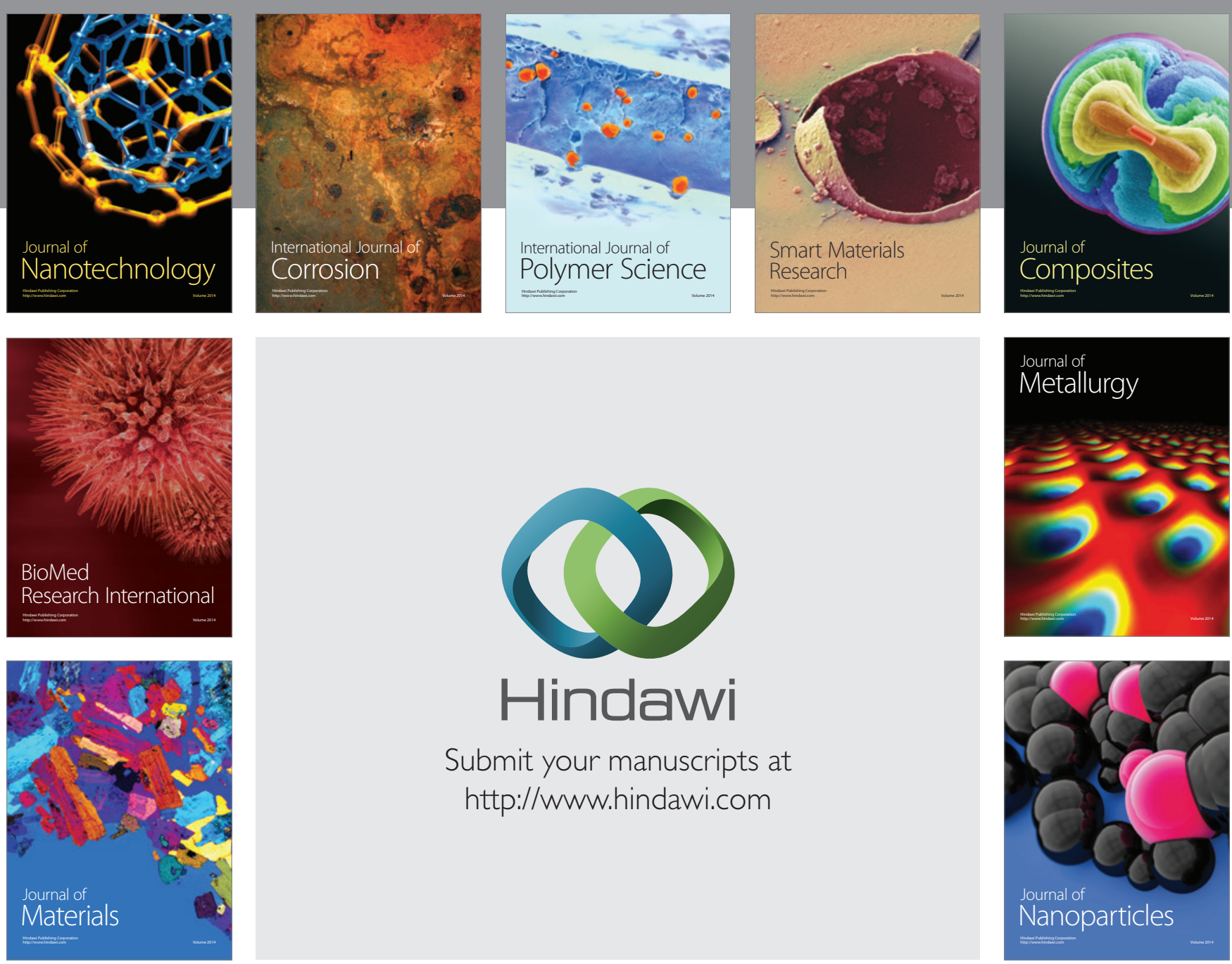

Submit your manuscripts at http://www.hindawi.com
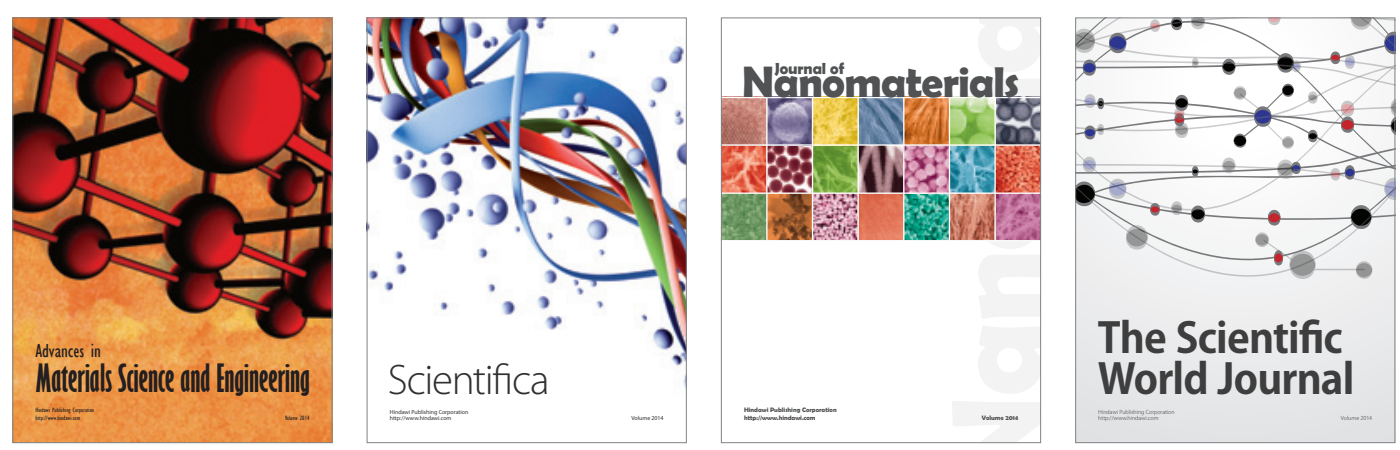

\section{The Scientific World Journal}
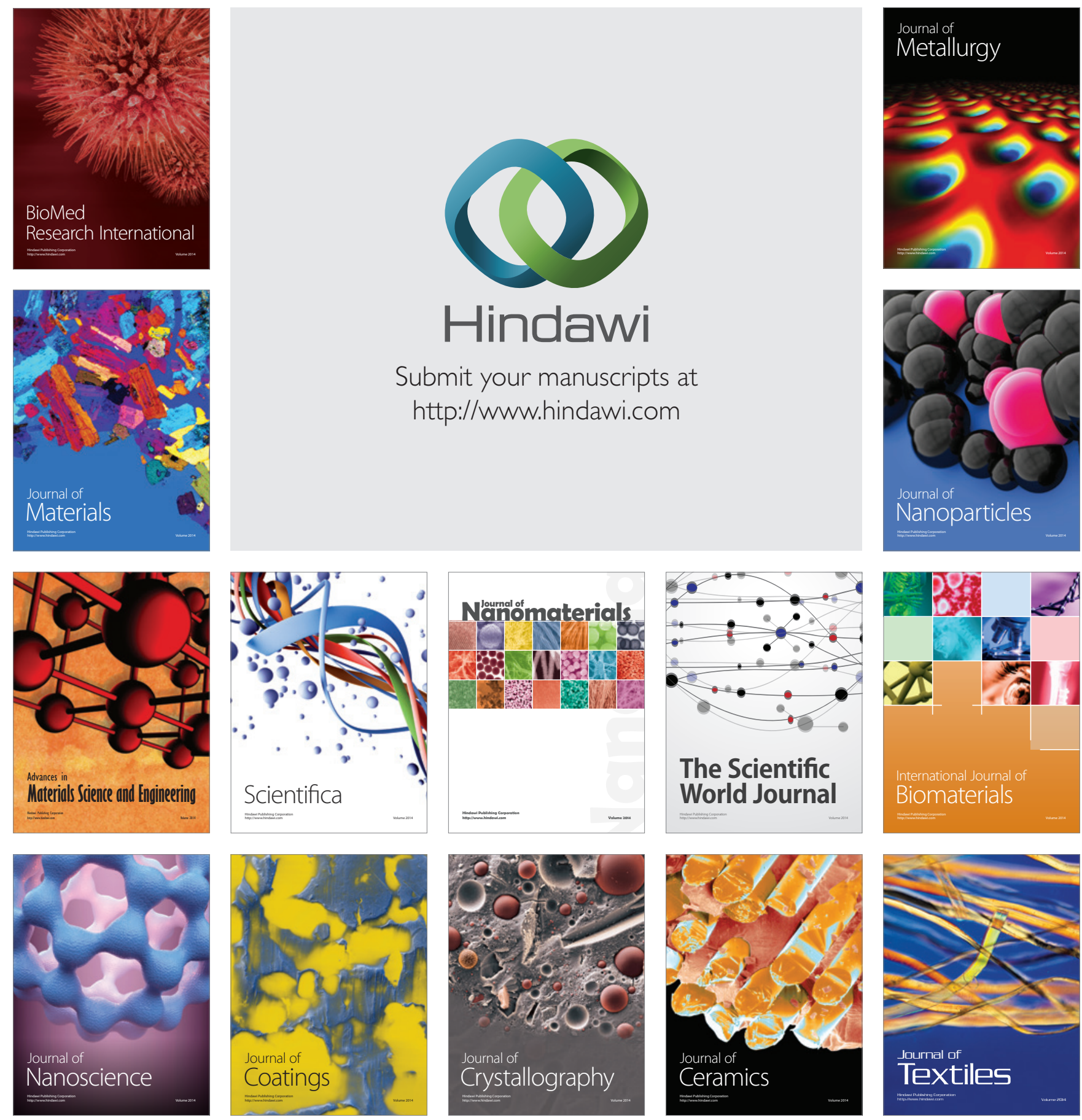